\title{
Suggestibility and performance in eyelid conditioning
}

\author{
Barbara Baker and Henry Loess \\ THE COLLEGE OF WOOSTER
}

\begin{abstract}
Performance in eyelid conditioning was found to be related to performance on one test of suggestibility (shock illusion) but not to another (body sway). In addition, inhibition of the UCR was found to be related to a failure to respond to the shock illusion. Less conclusive evidence indicated that voluntary responding may be related to performance on the body-sway test.
\end{abstract}

\section{Problem}

Das $(1958,1959)$ has reported a relationship between depth of hypnosis and performance in eyelid conditioning and has presented an hypothesis that hypnosis is a combination of a form of conditioning and a state of inhibition. The present study was originally designed to test Das' hypothesis. Hypnotizability was to be measured indirectly by using two tests of suggestibility (Eysenck \& Furneaux, 1945). However, since there is disagreement concerning the appropriateness of tests of suggestibility as evidence of hypnotizability (Duke, 1964) the study was modified to determine simply whether a relationship exists between eyelid conditioning and measures of suggestibility without reference to hypnosis.

\section{Method}

Sixty introductory psychology students were given two tests of suggestibility, a body-sway test (primary suggestibility) and a shock-illusion (secondary) test. Half the Ss received one test first, and half the other. For the body-sway test Ss stood parallel to a wall upon which 1-in marks were made. The measure used was the maximum sway observed in 2.5 min. during which $\mathrm{E}$ gave repeated suggestions that $S$ was falling. In the shock-illusion test $\mathrm{S}$ wore a glove through which shock could be delivered to the forefinger. Four trials were given ostensibly to determine Ss lower threshold for shock. On the third trial shock was not turned on. Each S was classified either as a "yes" responder or a "no" responder on the basis of his response on the third trial.

Forty Ss, 20 above and 20 below the median response on the body-sway test, were subsequently given 60 conditioning trials. Of the 40, 13 had responded "yes" and 27 "no" in the shock-illusion test. The ratio of females to males was approximately two to one in all subgroups. The eyelid apparatus was similar to that used in the Iowa laboratory. The CS was a light of $550 \mathrm{msec}$. duration; the UCS was a $3 \mathrm{lb}$ airpuff lasting $50 \mathrm{msec}$; the CS-UCS interval was $500 \mathrm{msec}$. Each $\mathrm{S}$ received three CS and two UCS presentations prior to to the first trial. The intertrial interval was a constant $20 \mathrm{sec}$. and no ready signal was used. A deflection greater than $1 \mathrm{~mm}$ in the interval 200-500 msec. was counted as a CR. The Ss were seated in a lighted room adjoining the one which housed the equipment.

\section{Results and Diseussion}

Curves for the four subgroups are presented in Fig. 1. The usual criteria for eliminating voluntary and inhibitory responders in eyelid experiments were not used since the experimental variables could have resulted in non-random distribution of such Ss among the subgroups. On the other hand, the inclusion of responses of atypical responders resulted in distributions which were highly skewed and variances which were not homogeneous. Therefore, the usual parametric statistical tests were not performed. A Mann-Whitney U-test, comparing the distributions of the total number of CRs for Ss scoring high and low on the body-sway test, was not significant $(z=1.40, P=.16)$. A U-test similarly applied to the data of "yes" and "no" responders on the shockillusion test was significant $(z=3.62, P<.001)$. These results indicate that performance in eyelid conditioning is related to secondary suggestibility (shock illusion) but not to primary suggestibility (body sway). In addition, scores on the two suggestibility tests were not significantly correlated with each other $(\mathrm{phi}=.037$ ).

Inspection of Fig. 1 shows an abnormally low group performance for the "no" responders. This suggests that the significant difference obtained between the "yes" and "no" groups may have been due to the

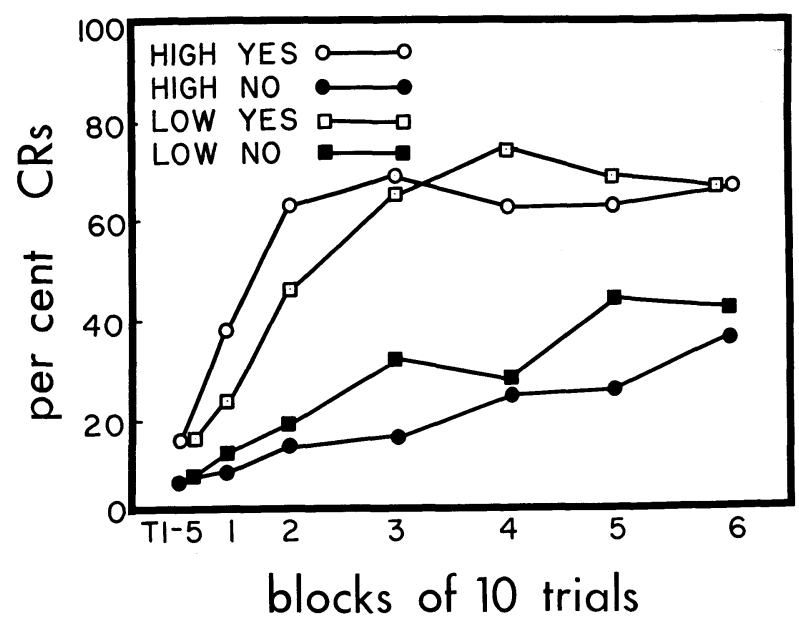

Fig. 1. Per cent CRs in eyelid conditioning as a function of performance on a body-sway test of suggestibility (high vs. low) and on a shock-illusion test of suggestibility (yes vs. no). 
Table 1. Number of Normal, Voluntary, and Inhibitory Responders and Performance on Two Tests of Suggestibility.

Normal Voluntary Inhibitory Total

Response to

Shock Illusion: yes no yes no yes no

$\begin{array}{llllllll}\text { High Body Sway } & 5 & 7 & 1 & 1 & 0 & 6 & 20 \\ \text { Low Body Sway } & 4 & 5 & 3 & 4 & 0 & 4 & 20\end{array}$

Total

$\begin{array}{lllllll}9 & 12 & 4 & 5 & 0 & 10 & 40\end{array}$

presence of inhibitory responders in the "no" groups. To test this, a judgment of inhibitory responder was made if the amplitude of an Ss CRs decreased by more than $50 \%$ over the 60 trials. Ten Ss met this criterion (Table 1). All were among the "no" responders on the shock-illusion test and all gave fewer than five CRs during conditioning, confirming that differences among the curves in Fig. 1 are due partially to the presence of inhibitors in the "no" groups. This supplements the results of Kimble \& Ost (1961) who found that inhibitors are poor conditioners and who suggested that inhibition of the UCR may be related to personality factors. The present data indicate that certain kinds of suggestibility may be among the personality factors involved.

Removal of the data of the ten inhibitors, however, does not eliminate the differences among the groups. A Mann-Whitney U-test comparing "yes" versus "no" responders (data of the ten inhibitors omitted) was still significant $(\mathrm{z}=2.53, \mathrm{P}=.01)$. This indicates that the superior performance of the "yes" groups is only partially explained by the presence of inhibitors in the "no" groups. Nor is the superiority of the "yes", groups explained by the presence of voluntary responders. As Table 1 indicates, only four of nine voluntary responders had responded "yes" to the shockillusion test. In the present study a judgment of voluntary was made if more than $50 \%$ of a Ss CRs exhibited the all-or-none type of closure usually attributed to a voluntary blink. A criterion of form rather than of latency was used since no ready signal hadbeen used in the experiment (Hartman \& Ross, 1961).

On the other hand, while voluntary responding, so defined, was not related to performance on the shockillusion test, seven of the nine voluntary Ss were among the low responders on the body-sway test $(P=.18)$. The obtained probability (two-tailed) is sufficiently high to suggest that the distribution of voluntary responders may well be due to chance. Nevertheless, it is suggested that investigators attempting to relate measures of suggestibility to performance in eyelid conditioning should pay special attention to the incidence and distribution of both inhibitory and voluntary responders.

Finally, it should be noted that of the two tests of suggestibility used in the present study, body sway, a test of "primary" suggestibility, has generally been found to be more highly correlated with direct tests of hypnotizability than has shock illusion, a test of "secondary," or sensory, suggestibility. Yet, in the present study, it was shock illusion rather than body sway which was significantly related to performance in eyelid conditioning. Thus, if body sway, but not shock illusion, is accepted as an indirect measure of hypnotizability, then the present study has failed to find a relationship between hypnotizability and conditioning.

\section{References}

DAS, J. P. Conditioning and hypnosis. J.exp. Psychol., 1958, 56, 110-113.

DAS, J. P. A theory of hypnosis. Int. J. clin. exp. Hypn., $1959,7,69-77$.

DUKE, J. D. Intercorrelational status of suggestibility tests and hypnotizability. Psychol. Rec., 1964, 14, 71-80.

EYSENCK, H. J., \& FURNEAUX, W. D. Primary and secondary suggestibility: an experimental and statistical study. J. exp. Psychol., 1945, 35, 485-503.

HARTMAN, T. F., \& ROSS, L. E. An alternative criterion for the elimination of "voluntary" responses in eyelid conditioning. J. exp. Psychol., 1961, 61, 334-338.

KIMBLE, G. A., \& OST, J. W. P. A conditioned inhibitory process in eyelid conditioning.J. exp. Psychol., $1961,61,150-156$. 